\title{
A novel MLH1 mutation harbored as a germ line aberration by a young woman of an HNPCC-like family and exhibited by a CML patient when occurring prior to the initiation of the blast phase concomitant with a c-MYC amplification
}

\author{
DORIT AMIKAM ${ }^{1,2,3}$, LUCY LESHANSKI $^{1}$ and MICHAL SAGI ${ }^{4}$ \\ ${ }^{1}$ Molecular Oncology Laboratory, Rambam Medical Center, Haifa; ${ }^{2}$ Department of Biotechnology and Environmental \\ Sciences, Tel-Hai Academic College, Tel-Hai; ${ }^{3}$ Sharett Institute of Oncology, Hadassah University Medical Center, \\ Ein-Kerem; ${ }^{4}$ Department of Human Genetics, Hadassah Hebrew University Hospital and Medical School, Jerusalem, Israel
}

Received November 17, 2005; Accepted January 8, 2006

\begin{abstract}
Germ line mutations in the MLH1 and MSH2 genes account for the majority of hereditary nonpolyposis colorectal cancer (HNPCC) families. Here, we describe a family that does not meet the international criteria for HNPCC, of which a young woman harbors a missense mutation (D132H). This novel germ line mutation has not previously been reported. Of the mismatch repair (MMR) genes, MLH1 has been shown to play an important role in hematologic malignancies. The novel mutation was also revealed to be a somatic aberration occurring prior to the initiation of the blast phase in a chronic myelogenous leukemia (CML) patient. Among the possible MLH1 partners involved in signaling MMR or apoptosis is the proto-oncogene c-MYC, which is closely related to cellular proliferation. We further revealed a concomitant c-MYC dramatic amplification in the CML-MLH1-mutation carrier patient, also occurring at the pre-blast phase. Our data contribute further to characterizing the mutational spectrum of the MLH1 gene. Furthermore, given the role of c-MYC and its interaction with MLH1, taken together with the mutational status of both genes revealed at the pre-blast phase in the CML patient, a plausible increased genetic instability might be expected to take place, possibly contributing to blast triggering. Our results may provide additional insight into the complex interplay between the MMR system and other cellular pathways.
\end{abstract}

Correspondence to: Dr Dorit Amikam, Department of Biotechnology and Environmental Sciences, Tel-Hai Academic College, Upper Galilee, 12210 Tel-Hai, Israel

E-mail: doritbenziman@bezeqint.net

Key words: MLH1 gene mutation, hereditary nonpolyposis colorectal cancer, chronic myelogenous leukemia

\section{Introduction}

Hereditary nonpolyposis colorectal cancer (HNPCC) is an autosomal-dominant disorder of cancer susceptibility with high penetrance $(1,2)$, which is thought to represent the most common form of familial colorectal carcinoma and account for approximately $1-6 \%$ of all colorectal cancers (1). The genetic basis of most HNPCC cases is a deficiency in DNA mismatch repair, leading to genomic instability in tumor cells. Thus far, the germ line mutations in 6 genes involved in DNA mismatch repair (MSH2, MLH1, PMS1, PMS2, MSH6 and MLH3) have been identified in HNPCC families (3). The clinical phenotype of HNPCC is variable, and there is no distinctive clinical hallmark. Therefore, stringent diagnostic criteria, essentially based on personal and family cancer history, namely the Amsterdam criteria, have been adopted for the purpose of identifying HNPCC families. MLH1 and MSH2 are considered to be the two major genes responsible for HNPCC (4), and approximately 40-50\% of families meeting the Amsterdam criteria have detectable MLH1 and MSH2 mutations (1). However, Amsterdam criteria can be too restrictive when applied to small kindreds abundant in Western countries (5), and there are sometimes difficulties in eliciting a complete and accurate cancer family history. A significant number of germ line mutations in the mismatch repair (MMR) genes have been detected in kindreds not meeting the Amsterdam criteria (6). Thus, identification of people predisposed to the disease would allow targeting of effective preventative measures, with the aim of reducing cancer-related mortality.

The mismatch repair gene MLH1, has been shown to play an important role in hematologic malignancies, and mutations in the gene were thought to be associated with the generation of constitutional genomic instability affecting, amongst others, downstream genes that are involved in rapidly proliferating cells such as possible leukemia-associated genes $(7,8)$. Extensive methylation of MLH1 was also shown to be associated with the presence of a defective DNA mismatch repair pathway in acute myeloid leukemia, resulting in microsatellite instability (MSI) as in solid tumors (9). 
Chronic myelogenous leukemia (CML) is a cancerous hematologic disease in which the initial relatively benign chronic phase is characterized by the accumulation of granulocyte lineage cells, maturation-arrested at a late stage of differentiation $(10,11)$. The acute phase that follows is a more malignant one and terminates with the blast phase at which the majority of circulating myeloid cells become blast cells, usually proving fatal within $6-12$ months $(10,11)$. Little is known about changes in the gene structure and expression that may accompany or even precede blastic transformation. The possibilities include, amongst other molecular events, genetic aberrations in proto-oncogenes involved in cellular proliferation. The proto-oncogene c-MYC is known to be closely related to cellular proliferation (12), and regulation of the cell cycle, differentiation and apoptosis (13).

In the present study, we describe a small family that does not meet the international criteria for HNPCC of which 2 patients were first degree relatives from two successive generations that died from colorectal cancer (CRC), one with an early onset of the disease. A novel germ line mutation in the MMR gene, MLH1 was discovered in the daughter of the latter patient, a finding that will allow effective follow-up for a possible manifestation of HNPCC. This novel germ line mutation was also found harbored by a CML patient as a somatic gene aberration, occurring in the pre-blast phase. Furthermore, a concomitant c-MYC dramatic amplification was also revealed in the CML-MLH1-mutation carrier patient at the same latter clinical phase. Taking into consideration that the proto-oncogene c-MYC interacts with MLH1 possibly in signaling MMR (14), and both genes were found to be mutated, a plausible increased genetic instability and elevated mutation rate might be expected to take place, a phenomenon that could contribute to blast triggering. Thus, our findings might provide additional insight into the MLH1-c-MYC relationship in tumorigenesis.

\section{Materials and methods}

DNA samples. A family that does not meet the international criteria for HNPCC and a CML patient were analyzed for possible MSH2 and/or MLH1 germ line mutations. DNA for analysis was isolated from whole blood using the standard procedure (15). Informed consent was obtained from each subject analyzed.

DNA sequencing. All exons and exon-intron junctions of the MSH2 and hMLH1 genes were amplified by PCR using Taq polymerase with 3' exonuclease activity, Ex Taq (Takara Co. Ltd., Tokyo, Japan). Primer sequences are the same as those previously reported (16-18). DNA sequencing was performed at commercial facilities using dye-terminator chemistry and automated sequencers (ABI models 377 and 3700; Applied Biosystems). Chromatogram and text files were analyzed with Chromas (version 1.45, http:// technelysium.com.au/chromas.html) and GeneRunner (version 3.04, Hastings Software Inc.) software, respectively. Forward and reverse sequencing was carried out, and mutations found in one PCR product were additionally confirmed in two independently amplified PCR products.

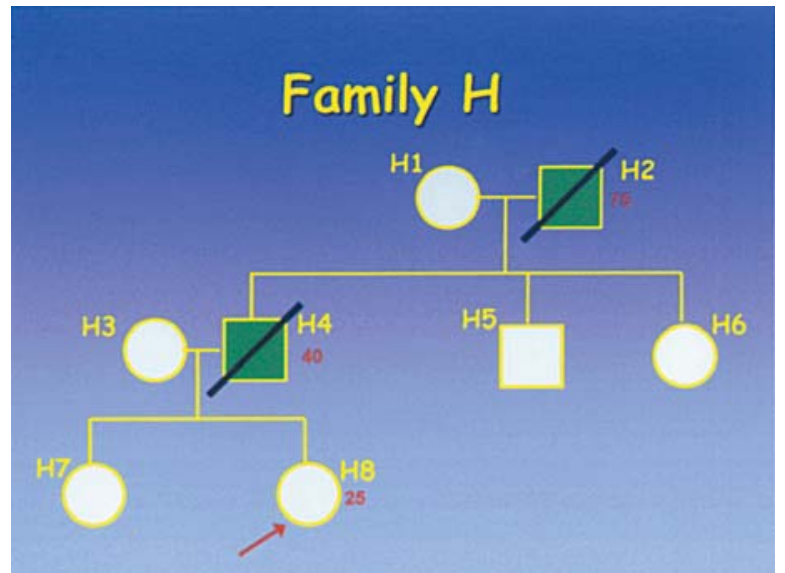

Figure 1. Schematic description of family H. Complete shading indicates a colorectal cancer-affected member. Arrow indicates the proband 25-year-old female at risk. When known, the age is noted.

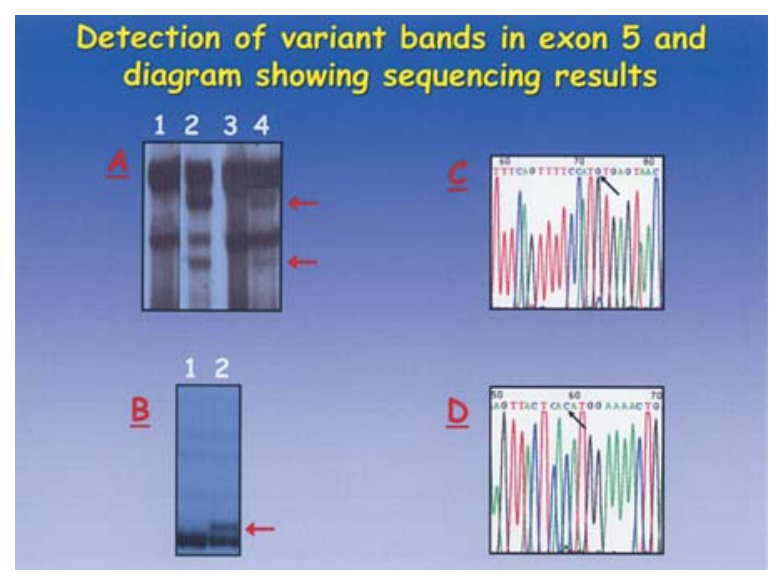

Figure 2. (A) Variant bands were seen (arrows) in subject H8 (lane 2) but not in the control (lane 1), and in the CML patient at the pre-blast phase (lane 4) but not at the chronic phase (lane 3) when PCR products were run on a 5\% polyacrylamide-5\% glycerol gel. (B) A variant band was seen (arrow) in subject H8 (lane 2) and not in the control (lane 1) when PCR products were run on $6 \%$ polyacrylamide gel. (C and D) Automated sequencing of the mutant allele was performed in both directions from genomic DNA in subject $\mathrm{H} 8$. The mutant allele showed a $394 \mathrm{G} \rightarrow \mathrm{C}$ transversion (arrows) in the normal sequence of AGTTACTCA $\underline{G}$ ATGGAAAACTG.

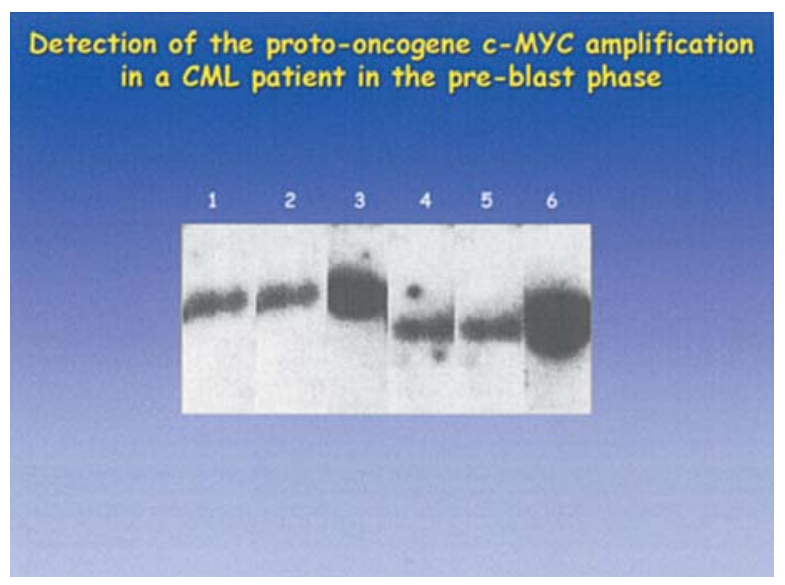

Figure 3. Southern blot analysis of normal DNA (lane 1, digested with EcoR1; lane 4, digested with HindIII) as the control, and the CML patient DNA at the chronic phase (lane 2, digested with EcoR1; lane 5, digested with HindIII) and pre-blast phase (lane 3, digested with EcoR1; lane 6, digested with HindIII), using the c-MYC probe. All reactions contained $5 \mu \mathrm{g}$ of DNA for enzymatic digestion. 
Southern blot analysis, DNA probe and hybridization. After digestion of DNA $(5 \mu \mathrm{g})$ with EcoRI and HindIII restriction endonucleases, the DNA was fractioned by electrophoresis on $0.8 \%$ agarose gel, blotted and hybridized to the pM c-myc 54 probe (19). The probe was end-labeled with gamma ${ }^{32} \mathrm{P}$ adenosine triphosphate and hybridization and autoradiography were carried out as described previously (20).

\section{Results}

Mutation analysis. As subject H4 died of CRC (Fig. 1) and a paraffin block sample could not be obtained, and other relatives of the young woman (subject H8) could not be approached to collect blood samples due to ethical reasons, we screened the DNA sample of the young woman for a possible germ line mutation in the MMR genes, MSH2 and MLH1. No MSH2 mutations were detected (data not shown). As seen in lane 2 of Fig. 2A, SSCP analysis with MLH1-exon 5 primers revealed unique variant bands. A unique variable band was also exhibited when employing a different set of gel conditions (Fig. 2B, lane 2). Sequencing analysis of the former variant bands from both directions (Fig. 2C and D) yielded a predicted missense mutation at codon 132 (D132H) due to a GAT to CAT transversion in exon 5, nucleotide 394 of the cDNA sequence. This alteration was not found when 100 normal unrelated individuals were analyzed (data not shown). Thus, the discovered gene aberration is a novel MLH1 mutation that has not been previously reported. Interestingly, the majority of exon 5 gene aberrations are known to be deletions contrary to the reported base substitution detected in subject $\mathrm{H} 8$.

Molecular studies of the CML patient. Since the mismatch repair gene MLH1 has been shown to play an important role in hematologic malignancies, and mutations in MLH1 were thought to be associated with constitutional genomic instability, a characteristic feature of CML patients during transformation to the irreversible blast phase, we wanted to evaluate the possibility of an MLH1 mutation harbored by the CML patient that was in the chronic phase at the time. As seen in lane 4 of Fig. 2A, variant bands identical to those obtained in subject H8 were revealed. Sequencing analysis of the variant bands from both directions confirmed the presence of the novel mutation discovered previously in subject H8. These unique variant bands were absent in the blood sample taken six months earlier, indicating that a somatic mutation had taken place; thus, a germ line status was ruled out (Fig. 2A, lane 3). The observed lower intensity of the variant bands, as exhibited by the CML patient, is in accordance with the results obtained earlier and imply that the latter acquired somatic mutation is not carried by all blood cells.

Since the CML patient exhibited an MLH1 mutation and MLH1 has been shown to interact with the proto-oncogene c-MYC, we sought to evaluate the c-MYC genetic status in the latter subject. For this purpose, DNA from both samples was subjected to the restriction enzymes EcoRI and HindIII, analyzed with Southern blotting and probed with c-MYC. As seen in Fig. 3, a notable dramatic amplification was observed (lanes 3 and 6). This amplification was absent when the first sample was studied (lanes 2 and 5).
Thus, the CML patient was found to harbor the novel MLH1 mutation and exhibited a concomitant dramatic amplification of the possible MLH1-MMR signaling partner, c-MYC, with both mutational events occurring at the preblast phase. Taken together and given the role the protooncogene has in cell cycle regulation, these gene aberrations might result in an increased mutation rate. The CML patient subsequently entered the blast phase and died five months after the second blood sample was taken.

\section{Discussion}

To date, a significant number of germ line mutations in the MMR genes have been detected in kindreds with a clustering of CRC not meeting the Amsterdam criteria (6). In this study, we describe a novel MLH1 germ line mutation carried by a young woman, subject $\mathrm{H} 8$, from a family meeting 3 of the 4 Amsterdam criteria. Segregation analysis and microsatellite instability assays may have been helpful in defining the exact pathogenic status of the mutation not previously reported, but the difficulty in obtaining biological material and blood samples of other relatives has precluded it. The novel aberration was not found in 100 unrelated individuals, and revealed to be a somatic mutation occurring at the pre-blast phase of a CML patient. Additionally, this missense mutation is situated at a highly conserved region (21). Taken together, the latter MLH1 novel transversion might therefore have pathological consequences. Although no clinical recommendations can be made before human validation (22), intensive followup is still warranted and thus recommended to subject $\mathrm{H} 8$. Interestingly, the detected MLH1 mutation is a single base substitution alteration, whereas the most frequently reported alterations in exon 5 are deletions.

Mutations in the MMR gene MLH1 were shown to play an important role in hematologic malignancies $(7,8)$. The mutation rates in tumor cells with an MMR deficiency are 100 - to 1000 -fold compared to normal cells $(23,24)$. An elevated mutation rate is characteristic of the transformation from chronic phase to blast phase in chronic myelogenous leukemia patients (25). The detected novel MLH1 mutation harbored by the CML patient, occurring at the specific time of the pre-blast phase, was concomitant with the revealed dramatic amplification of the proto-oncogene c-MYC. Loss of MMR can lead to a loss of cell cycle arrest, apoptosis induced by DNA damage and inappropriate progression through the cell cycle $(26,27)$. Similarly, deregulated c-MYC expression may result in DNA damage-induced apoptosis, a loss of cell cycle checkpoints and genetic instability (28-30). Furthermore, the proto-oncogene c-MYC has been shown to interact with the MLH1 gene (14) and is possibly an MLH1 signaling partner in MMR pathways. Thus, taken together and given the mutational genetic status of the CML patient, the reported genetic aberrations could have a pathologic significance for the CML patient, and our results might provide insight into the MLH1-c-MYC relationship in hematologic malignancies.

\section{References}

1. Lynch HT and de la Chapelle A: Genetic susceptibility to nonpolyposis colorectal cancer. J Med Genet 36: 801-818, 1999. 
2. Vasen HF, Watson P, Mecklin JP and Lynch HT: New clinical criteria for hereditary non-polyposis colorectal cancer (HNPCC, Lynch syndrome) proposed by the International Collaborative group on HNPCC. Gastroenterology 116: 1453-1456, 1999.

3. Peltomaki P: Deficient DNA mismatch repair: a common etiologic factor for colon cancer. Hum Mol Genet 10: 735-740, 2001.

4. Loukola A, de la Chapelle A and Aaltonen LA: Strategies for screening for hereditary nonpolyposis colorectal cancer. J Med Genet 36: 819-822, 1999.

5. Salovaara R, Loukola A, Kristo P, Kaariainen H, Ahtola H, Eskelinen M, Harkonen N, Julkunen R, Kanigas E, Ojala S, Tulikoura J, Valkamo E, Jarvinen H, Mecklin JP, Aaltonen LA and de la Chapelle A: Population-based molecular detection of hereditary nonpolyposis colorectal cancer. J Clin Oncol 18: 2193-2200, 2000

6. Genuardi M, Anti M, Capozzi E, Leonardi F, Fornasarig M, Novella E, Bellacosa A, Valenti A, Gasbarrini GB, Roncucci L, Benatti P, Percesepe A, Ponz de Leon M, Coco C, de Paoli A, Valentini M, Boiocchi M, Neri G and Veil A: MLH1 and MSH2 constitutional mutations in colorectal cancer families not meeting the standard criteria for hereditary nonpolyposis colorectal cancer. Int J Cancer 75: 835-839, 1998.

7. Ricciardone MD, Ozcelik T, Cevher B, Ozdag H, Tuncer M, Gurgey A, Uzunalimoglu O, Cetinkaya H, Tanyeli A, Erken E and Ozturk M: Human MLH1 deficiency predisposes to hematological malignancy and neurofibromatosis type I. Cancer Res 59: 290-293, 1999.

8. Wang Q, Lasset C, Desseigne F, Frappaz D, Bergeron C, Navarro C, Ruano E and Puisieux A: Neurofibromatosis and early onset of cancers in hMLH1-deficient children. Cancer Res 59: 294-297, 1999.

9. Seedhouse CH, Das-Gupta EP and Russell NH: Methylation of the hMLH1 promoter and its association with microsatellite instability in acute myeloid leukemia. Leukemia 17: 83-88, 2003.

10. Galton D: The chronic leukemias. In: Postgraduate Haematology, 2nd edition. Hoffbrand AV and Lewis SM (eds). Wm. Heinemann Medical Books, London, pp478-512, 1981.

11. Clarkson B: The chronic leukemias. In: Cecil Textbook of Medicine. Wyngaarden JB and Smith LH (eds). WB Saunders, Philadelphia, pp975-986, 1986.

12. Obaya AJ, Mateyak MK and Sedivy JM: Mysterious liaisons: the relationship between c-Myc and the cell cycle. Oncogene 18: 2934-2941, 1999.

13. Henriksson M and Luescher B: Proteins of the Myc network: essential regulators of cell growth and differentiation. Adv Cancer Res 68: 109-182, 1996.

14. Partlin MM, Homer E, Robinson H, McCormic CJ, Crouch DH, Durant ST, Matheson EC, Hall AG, Gillespie AFD and Brown R: Interaction of the DNA mismatch repair proteins MLH1 and MSH2 with c-MYC and MAX. Oncogene 22: 819-825, 2003.

15. High KA, Ware JL and Stafford DW: Isolation of genomic DNA, restriction endonuclease mapping and Southern gene blotting. In: Molecular Genetics Methods in Hematology. Benz EJ (ed). Churchill Livingstone, Edinburgh, pp21-36, 1989.
16. Kolodner RD, Hall NR, Lipford J, Kane MF, Rao MR, Morrison P, Wirth L, Finan PJ, Burn J and Chapman P: Structure of the human MSH2 locus and analysis of two Muir-Torre kindreds for msh2 mutations. Genomics 24: 516-526, 1994.

17. Kolodner RD, Hall NR, Lipford J, Kane MF, Morrison PT, Finan PJ, Burn J, Chapman P, Earabino C and Merchant E: Structure of the human MLH1 locus and analysis of a large hereditary nonpolyposis colorectal carcinoma kindred for mlh1 mutations. Cancer Res 55: 242-248, 1995.

18. Wu Y, Nystrom-Lahti M, Osinga J, Looman MW, Peltomaki P, Aaltonen LA, de la Chapelle A, Hofstra RM and Buys CH: MSH2 and MLH1 mutations in sporadic replication errorpositive colorectal carcinoma as assessed by two-dimensional DNA electrophoresis. Genes Chromosomes Cancer 18: 269-278, 1997.

19. Stanton LW, Watt R and Marcu KB: Translocation, breakage and truncated transcripts of c-myc oncogene in murine plasmacytomas. Nature 30: 401-406, 1983.

20. Mills KI, MacKenzie ED and Birnie GD: The site of the breakpoint within the bcr is a prognostic factor in Philadelphiapositive CML patients. Blood 72: 1237-1241, 1988.

21. Han HJ, Maruyama M, Baba S, Park JG and Nakamora Y: Genomic structure of human mismatch repair gene, hMLH1, and its mutation analysis in patients with hereditary nonpolyposis colorectal cancer (HNPCC). Hum Mol Genet 4: 237 $242,2000$.

22. Syngal S, Fox EA, Li C, Dovidio M, Eng C, Kolodner RD and Garber JE: Interpretation of genetic test results for hereditary nonpolyposis colorectal cancer: implication for clinical predisposition testing. JAMA 282: 281-282, 1999.

23. Parsons R, Li GM, Longley MJ, Fang WH, Papdopoulos N, Jen J, de la Chapelle A, Kinzler KW, Vogelstein B and Modrich P: Hypermutability and mismatch repair deficiency in $\mathrm{RER}^{+}$tumor cells. Cell 75: 1227-1236, 1993.

24. Bhattacharyya NP, Skandalis A, Ganesh A, Gordon J and Meuth M: Mutator phenotypes in human colorectal carcinoma cell lines. Proc Natl Acad Sci USA 91: 6319-6323, 1994.

25. Preiler HD: A hypothesis regarding the development of acute myeloid leukemia from preleukemic disorders. The role of protooncogenes. Cancer Genet Cytogenet 32: 133-142, 1988.

26. Hawn MT, Umar A, Carethers JM, Marra G, Kunkell TA, Boland CR and Koi M: Evidence for a connection between the mismatch repair system and the G2 cell cycle checkpoint. Cancer Res 55: 3721-3725, 1995 .

27. Strathdee G, Sansom OJ, Sim A, Clarke AR and Brown R: A role for mismatch repair in control of DNA ploidy following DNA damage. Oncogene 20: 1923-1927, 2001.

28. Prendergast GC: Mechanisms of apoptosis by c-Myc. Oncogene 18: 2967-2987, 1999

29. Flesher DW and Bishop JM: Transient excess of MYC activity can elicit genomic instability and tumorigenesis. Proc Natl Acad Sci USA 96: 3940-3944, 1999.

30. Adachi S, Obaya AJ, Han Z, Ramos-Desimone N, Wyche J and Sedivy JM: c-Myc is necessary for DNA damage-induced apoptosis in the G(2) phase of the cell cycle. Mol Cell Biol 21: 4929-4937, 2001 